\title{
Analysis of Pi and Adaptive Fuzzy Based Speed Control of PMSM Using Flux Weakening Operation
}

\author{
${ }^{1}$ R. Gopala Krishnan, ${ }^{2}$ Mr.S.Vijaya Baskar \\ ${ }^{I}$ Pg Scholar, Department Of PG-ES P.A College Of Engineering and Technology \\ Pollachi, India \\ ${ }^{2}$ Associate Professor, Department of EEE P.A College of Engineering and Technology Pollachi, India
}

\begin{abstract}
This paper proposed to regulate the speed control of PMSM with PI and Adaptive fuzzy based speed control using flux weakening operation. In this method with having advantages in permanent magnet synchronous machine (PMSM) drive can utilization and widen flux weakening region the maximum utilization of inverter output regulated current saturation makes the instantaneous current control capability. This paper proposed using current control regulation by flux weakening operation controller by VSI fed inverter side with SVPWM gate pulsed to operate the IGBT fed inverted drive circuit with dynamic performance of current control. Adopted fuzzy controller compares the error signal and change in error signal to the PI control with $K_{p}$ and $K_{i}$ value. The simulation and experimental results are taken by MATLAB SIMULINK with considering with stator current control regulated wave forms.
\end{abstract}

Keywords: PMSM (permanent magnet synchronous motor), SVPWM (space vector pulse width modulation), VSI (voltage source inverter)

\section{Introduction}

The permanent magnet synchronous motor can be competing with an induction machine mainly in low power range. The advantage of the PMSM with two type's surface mounted PMSM and interior PMSM with high proportional inertia torque, high speed range and proptional to its electromagnetic torque. Permanent magnet synchronous machine (PMSM) is speed of the rotor is proportional. To regulate the capability of the output the voltage of the inverter increased proportionally to the speed. The inverter is limited by the DC-link voltage which makes the physical limitation of the operating speed in the machine. To overcome of the PMSM drive $d$ axis current to the $q$ axis current regulation in flux weakening operation [1][2]. The motor power is fully utilization by its characterized inverter output. The fundamental of the component in the inverter output is maximum for limitation of speed. Steady state operation is to be considered neglecting the current regulation with not consideration of transient behavior. Closed loop control regulation is used to control the normal set parameter speed to its reference speed. In order to instantaneous current control with closed loop current regulation control is needed with nonlinear modeling of voltage flux weakening operation [6][8]. This paper proposed with adopted fuzzy based system with error signal and change in error signal compared with Pi in ( $\mathbf{K}_{\mathbf{p}}$ and $\mathbf{K}_{\mathbf{i}}$ ) value.

\section{Mathematical Model Of PMSM}

The two axes PMSM stator winding can be considered to have equal turns per phase. The rotor flux can be assumed to be concentrated along the $\mathrm{d}$ axis while there is zero flux along the $\mathrm{q}$ axis while there is zero flux along the $\mathrm{q}$ axis an assumption similarly made in the derivation of indirect vector control like induction motor drives. Future the machine core loss is negligible. Also rotor flux is assumed to be constant as the given operating point. Variations in rotor temperature alter the magnetic flux, but it varies with time considered to be neglected. There is no need to include the rotor voltage equation and variation in the rotor flux with respect to time is negligible from that Stator voltage equation is derived from following equation (1)

$$
\left[\begin{array}{c}
V^{v} q s \\
V^{v} d s
\end{array}\right]=\left[\begin{array}{cc}
R_{q}+L_{q} & \omega_{R} L_{d} \\
-\omega_{R} L_{q} & R_{d}+L_{d} p
\end{array}\right]\left[\begin{array}{c}
i^{\gamma} q_{s} \\
i^{\gamma} d_{g}
\end{array}\right]+\left[\begin{array}{c}
\omega_{r} L_{m i} f_{r} \\
0
\end{array}\right]
$$

The positive $a_{g}, b_{g}, c_{g}$ are drawn in the direction of negative flux linkage relative to the assumed positive direction of stator current from following equation (2).

$$
\left[\begin{array}{c}
\lambda_{a b c s} \\
\lambda_{q d r}
\end{array}\right]=\left[\begin{array}{cc}
L_{g} & L_{s r} \\
L_{g r} T & L r
\end{array}\right] \quad\left[\begin{array}{c}
-i_{a b e s} \\
i_{q} d r
\end{array}\right]
$$




$$
\begin{aligned}
& V_{d}=R i_{d}+L_{d} \frac{d_{\text {id }}}{d t}-L_{q} \omega_{s} i_{q} \\
& V_{q}=R i_{q}+L_{q} \frac{d_{\text {iq }}}{d t}-L_{d} \omega_{s} i_{d}+\omega_{s} \psi_{f} \\
& \psi_{d}=L_{d} i_{d}+\psi_{f} \\
& \psi_{q}=L_{q} i_{q}
\end{aligned}
$$

The stator equations of the rotor reference frame using flux linkages are taken to the model of PMSM. The rotor frame of reference is chosen the position of the motor magnetic to be determined independently of the stator voltage and current, the instantaneous induced emf and sub sequentially the rotor current. The rotor fluxes are not independent variables that are influenced by the stator voltage and current. When the rotor reference frames are considered it means the equivalent $\mathrm{q}$ and $\mathrm{d}$ axis stator winding are the reference frame are considered that are revolving at rotor speed. The consequence is that there is zero speed difference between the rotor and stator magnetic fields and the stator $\mathrm{q}$ and $\mathrm{d}$ axis winding have rotor magnet axis which is the $\mathrm{d}$ axis in the modeling in equation(7)(8)

$$
\begin{aligned}
& V^{r}{ }_{\mathrm{qs}}=\mathrm{R}_{\mathrm{q}} \mathrm{i}_{\mathrm{qs}}^{\mathrm{r}}+\mathrm{p} \lambda_{\mathrm{qs}}^{\mathrm{r}}+\omega_{\mathrm{r}} \lambda_{\mathrm{ds}}^{\mathrm{r}} \\
& V^{r}{ }_{\mathrm{ds}}=\mathrm{R}_{\mathrm{d}} \mathrm{i}_{\mathrm{ds}}^{\mathrm{r}}+\mathrm{p} \lambda_{\mathrm{ds}}^{\mathrm{r}}+\omega_{\mathrm{r}} \lambda_{\mathrm{qs}}^{\mathrm{r}}
\end{aligned}
$$

Where $R_{q}$ and $R_{d}$ are the quadrature and direct axis winding resistance which are equally to the stator resistance and the $\mathrm{q}$ and $\mathrm{d}$ axis stator flux linkage in the rotor reference frame are

$$
\begin{aligned}
& \lambda_{\mathrm{qs}}^{\mathrm{r}}=\mathrm{L}_{\mathrm{s}} \mathrm{i}_{\mathrm{qs}}^{\mathrm{r}}+\mathrm{L}_{\mathrm{m}} \mathrm{i}_{\mathrm{qr}}^{\mathrm{r}} \\
& \lambda_{\mathrm{ds}}^{\mathrm{r}}=\mathrm{L}_{\mathrm{s}} \mathrm{i}_{\mathrm{ds}}^{\mathrm{r}}+\mathrm{L}_{\mathrm{m}} \mathrm{i}^{\mathrm{r}}{ }_{\mathrm{dr}}
\end{aligned}
$$

But the self-inductance of the stator $\mathrm{q}$ and $\mathrm{d}$ axis winding are equal to Ls only when the rotor magnets have an electrical $180^{\circ}$. This has the implication that the reluctances along the magnet axis and the impolar axis are different. when a stator winding is in alignment with the rotor magnetic axis and the interpolar axis is different. when a stator winding is in alignment with the rotor magnetic axis the reluctance path is maximum. The magnet reluctance is almost the air gap reluctances. The permanent magnet excitation can be modeled as a constant current source, $i_{\mathrm{fr}}$. The rotor flux is along the $\mathrm{d}$ axis, so the $\mathrm{d}$ axis rotor current is $i_{\mathrm{fr}}$. The $\mathrm{q}$ axis current in the rotor side is zero, because there is no flux along this axis in the rotor, by assumption. The flux linkage equation is derives as

$$
\lambda_{\mathrm{qs}}^{\mathrm{r}}=\mathrm{L}_{\mathrm{q}}{ }^{\mathrm{r}}{ }_{\mathrm{qs}}
$$

$$
\lambda_{\mathrm{ds}}^{\mathrm{r}}=\mathrm{L}_{\mathrm{d}} \mathrm{i}_{\mathrm{ds}}^{\mathrm{r}}+\mathrm{L}_{\mathrm{m}} \mathrm{i}_{\mathrm{fr}}
$$

Flux linkage into the stator voltage equations gives the stator equations the electro magnetic torque is given by

$$
\mathrm{Te}=\frac{3}{2} \frac{p}{2}\left\{\lambda_{\mathrm{af}} \mathrm{i}_{\mathrm{qs}}^{\mathrm{r}}+(\mathrm{Ld}-\mathrm{Lq}) \mathrm{i}_{\mathrm{qs}}^{\mathrm{r}} \mathrm{i}_{\mathrm{ds}}^{\mathrm{r}}\right\}
$$

\section{Current Harmonics and Torque Ripple Of PMSM}

The voltage equation of three phases PMSM can be expressed by

$$
\begin{aligned}
& V_{a}=R_{s} i_{a}+L_{g} \frac{d}{d_{t}}+i_{a}+e_{a} \\
& V_{b}=R_{a} i_{b}+L_{g} \frac{d}{d_{t}}+i_{b}+e_{b} \\
& V_{c}=R_{g} i_{c}+L_{g} \frac{d}{d_{t}}+i_{c}+e_{c}
\end{aligned}
$$

From the equation (14)(15)(16) Where $R_{g}$ is the equivalent resistance of the stator $L_{g}$ in the equivalent inductor of the stator $V_{a}, V_{b}, V_{c}$ are the three phase voltages of the stator $i_{a}, i_{b}, i_{c}$ three phase current of the stator $e_{\tilde{\alpha},} e_{b}, e_{c}$ are the thee phase back EMF of the motor

\section{Control Strategies in PMSM}

The torque and speed in control angle provides a wide variation of control choices in PMSM drive system

i. Constant torque and angle control or zero direct axis current control.

ii. Unity power factor control.

iii. Constant mutual air gap flux linkages control 
iv. Optimum torque per ampere control.

v. Flux weakening control.

$>$ Variable frequency control

\section{Control Methods in PMSM:}

- Scalar bases with voltage/ frequency

$>$ Vector based

- Field oriented control with rotor flux oriented (direct and indirect) and stator flux oriented control with closed loop flux and torque control

- Direct torque control.

\section{Flux Weakening Operation:}

The rated flux linkages up to a speed where the ration between the induced emf and stator frequency, known as voltage/ $\mathrm{Hz}$, with neglected the stator impedance, can be maintained constantan rated value. After the stator frequency, known as the base frequency, the volts/Hz ratio, and hence the stator flux linkage, will be lower than its rated value that is due to fixed dc-link voltage magnitude. The operation above the base speed necessarily involves the weakening of the flux, resulting in the reduction of torque for the same torque producing component of the stator current.

By coordinating the torque level for each operating speed, the power output is maintained constant in the flux weakening region. It existed to its direct scheme and indirect scheme flux linkage drive system. In order to produce the maximum torque, which main component is proportional to q-axis component of the armature current it is convenient to control the inverter-fed PMSM by keeping the direct, d-axis, current component to be $i_{d}$ to zero as long as the inverter output voltage doesn't reach its limit At that point, the motor reaches its maximum speed, so-called rated speed (Called also base speed when talking about flux-weakening). Beyond that limit, the motor torque decreases rapidly toward its minimum value, which depends on a load torque profile. To expand the speed above the rated value, the motor torque is necessary to be reduced.

A common method in the control of synchronous motors is to reduce the magnetizing current, which is produces in the magnetizing flux. This method is known as field-weakening. With PM synchronous motors it is not possible, but instead the air gap flux is weakened by producing a negative $d$-axis current component, $i_{d}$ current component. Because nothing has happened to the excitation magnetic field and the air gap flux is still reduced, in the motor torque, this control and constant method is called flux-weakening.

As a basis for this analysis, the PMSM current and voltage d-q vector are used. During flux-weakening, because the demagnetizing (negative current) $i_{d}$ current increases, a phase current vector $i_{s}$ rotates toward the negative d-semi axis[3][4]. The rotation of the phase voltage vector is determined by a chosen flux-weakening strategy, but at the end of flux-weakening it always rotates toward the positive q-semi axis because of $i_{q}$ current, $\mathrm{v}_{\mathrm{d}}$ voltage magnitude decrease. Hence, the voltage-to-current phase shift decreases to zero and increases in negative direction either to the inverter phase shift limit or a load torque dictated steady-state (zero acceleration), or to the zero motor torque condition (no load or generative load). A big concern of fluxweakening control is a danger of permanent demagnetization of magnets.

The rotor flux linkage and rotor speed is represented and

Two approaches are considered in this control approach.

1) The demagnetization current is pre determined only by rotor speed. This approach is called direct

2) The demagnetizing stator current is derived as a function for not only with rotor speed but also the electromagnetic torque. This method is refers to as indirect approach.

Flux linkage can specified in two parameters assumption in

- Rotor linkage flux

- Stator linkage flux

In most predictable control for the speed rotor axis flux is considered.

\section{Methods Adopted For Flux Weakening Controller}

- Direct flux weakening

- Indirect flux weakening

The direct flux weakening algorithm demagnetizing component of stator current satisfying the maximum current and voltage only. It is very simple to the field control separately excited dc machines where the field current is determined usually by the speed alone this method has advancialy simplicity. The PMSM drive system control with speed, torque and power. 
In indirect flux weakening Alternative flux weakening control strategy is based on controlling directly the mutual flux linkages which is inversely proportional to the electrical rotor speed [4][6]. This is very simple to control the field flux of the separately excited motor the flux weakening where the dc link voltage and hence the stator voltage phase magnitude is constant, the mutual flux linkage has been inversely proportional to the rotor electric speed. Such control forward to the high speed and low speed operation. In order to incorporate any control strategy (such as maximum torque per ampere, constant air gap flux linkage, unity power factor or constant torque angle) below the base speed region the corresponding mutual flux linkages base speed in order to work within the link voltage. The machine will operated with in the limited dc-link voltage. The machine will operate maximum speed mutual flux linkages. Mutual flux linkage weakening and torque controls and incorporate in a speed-control system output from PI controller [7]. The command processor weakens the torque to the speed is higher than the one per unit in order to limit the machine power. The command processor also generates the mutual flux linkage command. The mutual flux weakening operated to its base speed which could be less than or equal to one p.u (per unit).

In both the flux weakening estimation with sensorless control of PMSM drive required two current sensors and an absolute rotor position sensor for implementation of any control strategy. The rotor position is sensed by an optical encoder or resolution for high performance application. The position sensor compares to the cost very none compensating other type of motor drives [9]. The control and operation of PMSM drive without a rotor position sensor based drive during sensor failures.

The basic for this control strategy that the error between measured and calculated current from the machine model gives the different between the actual rotor speed and the reference speed of the motor drive by estimating the rotor position accurately. Two phase current constitute the input to the electrical rotor position the error between the estimated rotor speeds.

\section{Flux Weakening Algorithm}

Steady state voltage equation are derived

$$
\begin{aligned}
& V_{q}=R_{s} i_{q}+\omega_{r} L_{d} i_{d}+\omega_{r} \varphi_{f} \\
& V_{d}=-\omega_{r} L_{q} i_{q}+R_{s} i_{d}
\end{aligned}
$$

Constant power at zero torque $\mathrm{q}$ axis current is zero

$$
\begin{gathered}
V_{q}=\omega_{r} L_{d} i_{q}+\omega_{r} \varphi_{f} \\
V_{q}=-R_{s} i_{d}
\end{gathered}
$$

The maximum value of the speed maximum average inverter

$$
\omega_{r} \max =\frac{\sqrt{V_{s}^{2}-R_{s}{ }^{2}} i_{d}}{\omega_{f}+i_{d} L_{d}}
$$

Positive giving condition of maximum stator current counters the permanent magnet flux linkage as

$$
i_{d} \max \left(\frac{-\omega_{f}}{L_{d}}\right)
$$

\section{Speed Control Scheme}

The flux linkage weakening and torque control are incorporate in a speed control with PI and adaptive fuzzy system. The process weakens the machine order to limited the power. Speed control designed view from desired transient and steady state characteristic to the speed control of PMSM drive system. The proportional integral controller (PI) for many industrial applications. In the presents of $\mathrm{d}$ axis stator current, the $\mathrm{d}$ and $\mathrm{q}$ current channels with linear scheme.

\section{$\mathrm{X} . \quad$ dq to $\mathrm{ABC}$ Convention and $\mathrm{ABC}$ To dq Conversion}

Considering the coordination transformation of the matrix and inverse transformation to $\mathrm{dq} 0$ axis the transformation matrix and inverse transformation of dq axis

$$
T^{y} q_{d 0}=\frac{2}{3}\left[\begin{array}{ccc}
\cos \theta_{r} & \cos \left(\theta_{r}-120\right) & \cos \left(\theta_{r}+120\right) \\
\sin \theta_{r} & \sin \left(\theta_{r}+120\right) & \sin \left(\theta_{r}+120\right) \\
\frac{1}{2} & \frac{1}{2} & \frac{1}{2}
\end{array}\right]
$$




$$
T^{r} q_{d 0^{-1}}=\left[\begin{array}{ccc}
\cos \theta_{y} & \cos \theta_{y} & 1 \\
\cos \left(\theta_{y}-120\right) & \sin \left(\theta_{y}+120\right) & 1 \\
\cos \left(\theta_{y}+120\right) & \sin \left(\theta_{y}+120\right) & 1
\end{array}\right]
$$

From the simulation work proposed with derived model as dq transformation to $\mathrm{ABC}$ and $\mathrm{ABC}$ to $\mathrm{dq}$ transformation is derived as mathematical model of dq /abc

$\mathrm{U}(1) * \cos (\mathrm{u}(4))+\mathrm{u}(2) * \sin (\mathrm{u}(4))+\mathrm{u}(3)$

$\mathrm{U}(1) * \cos (\mathrm{u}(4)-2 * \mathrm{pi} / 3)+\mathrm{u}(2) * \operatorname{sinu}(4)-2 * \mathrm{pi} / 3+\mathrm{u}(3)$

$\mathrm{U}(1) * \cos (\mathrm{u}(4)+2 * \mathrm{pi} / 3)+\mathrm{u}(2) * \sin (\mathrm{u}(4)+2 * \mathrm{pi} / 3+\mathrm{u}(3)$

\section{Fuzzy Logic and Membership Declaration}

For more predictable control, high performance of motor drive, accurate motor speed control regard to sudden load change and variation in parameter assumption to ensure the speed control operation compared to $\mathrm{P}$, PI, PID control required some mathematical model for design. The advantage of the fuzzy system does not regulated with mathematical model. Fuzzy based system model is used for various machines like BLDC, and induction motor

E.g.: Fuzzy based system is preferred for the direct drive washing machine.

Fuzzy system is noted to be knowledge based or ruled based adopted by human thinking. For input of fuzzy controller is the error signal and change in error signal. This process which compared to the error signal and change in error signal at sampling period.

Fuzzy system operated at knowledge based it is main heart for fuzzy operation. Defined by ruled set of logical function condition IF-THEN rule. The rules are selected depend human intelligent control and knowledge is defined by system behavior.

Normally the basic configuration of fuzzy logic is mounted with the following FLC component.

- Input interface of Fuzzification crisp input value.

- Processing with knowledge based specific rules.

- Decisions making logic.

- Defuzzification interface as crisp output.

The input and output values are specified using various membership functions like triangular, trapezoidal, Gaussian, Generalisedbell, sigmoid, left right membership functions are used in fuzzy control.

Fuzzy rules are specified with Mamdani, sugino and sugimoto.

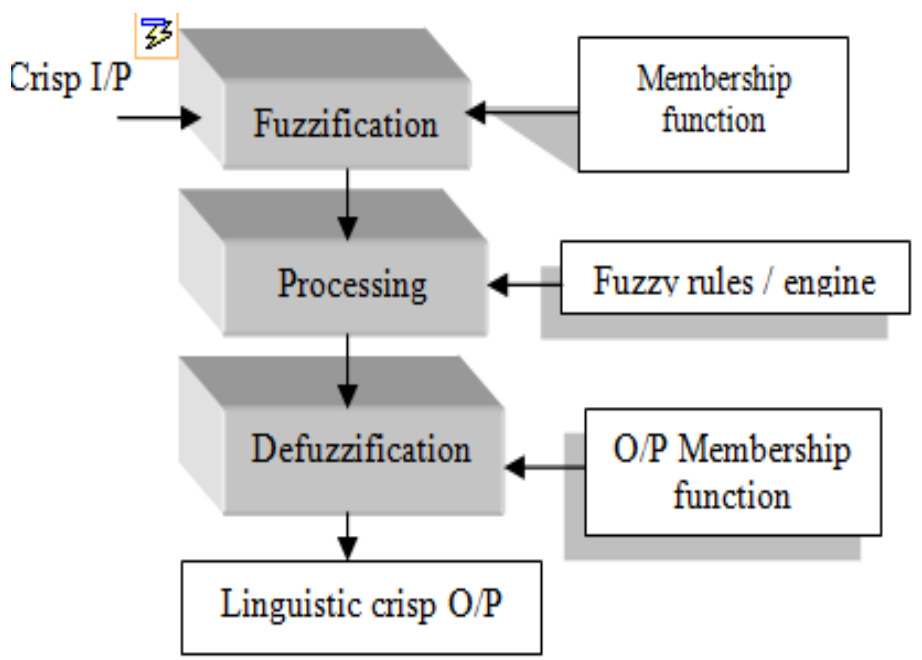


XII. Simulation and Output Wave Form

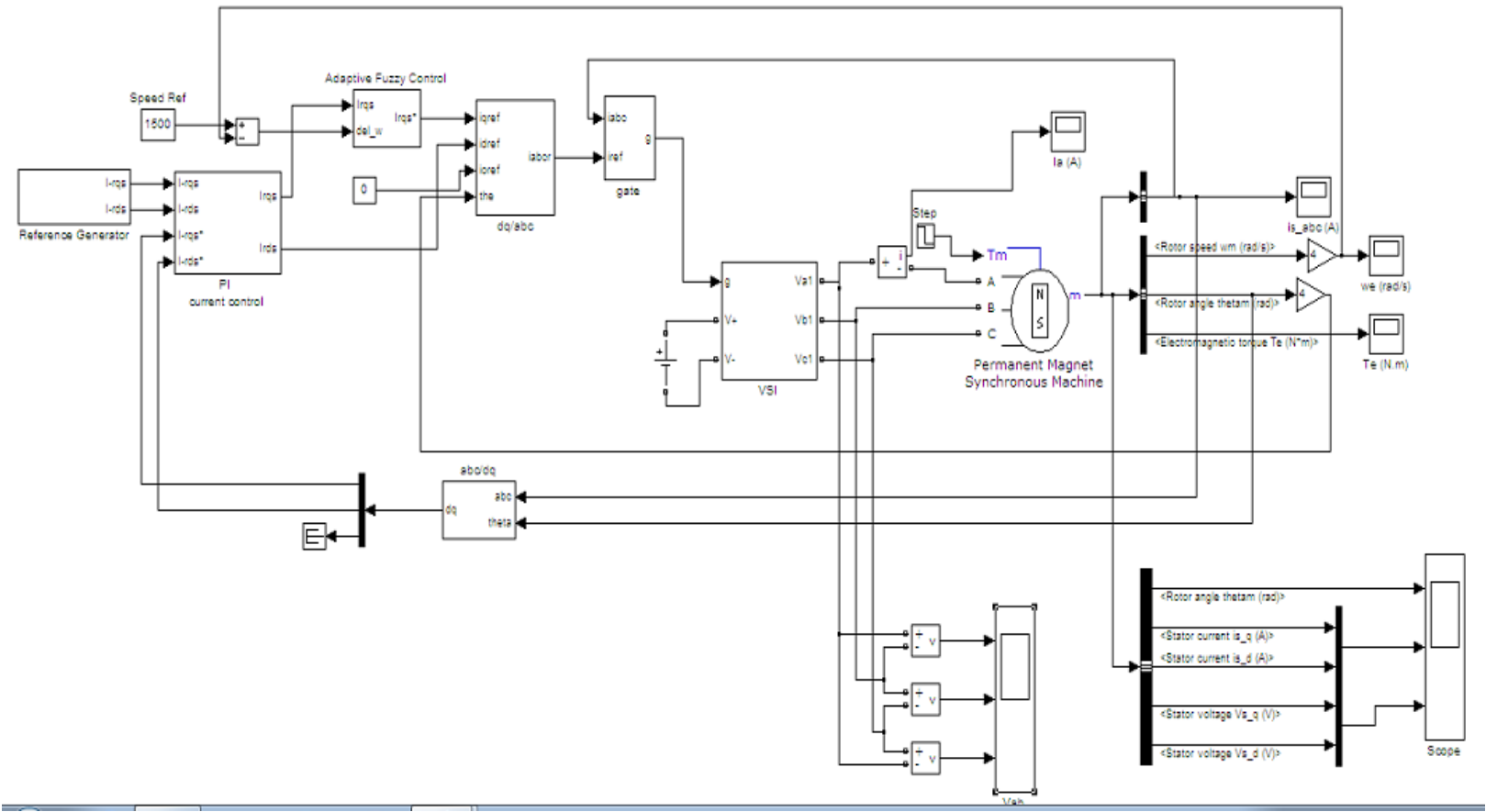

Figure 12.1 simulation diagram of PMSM

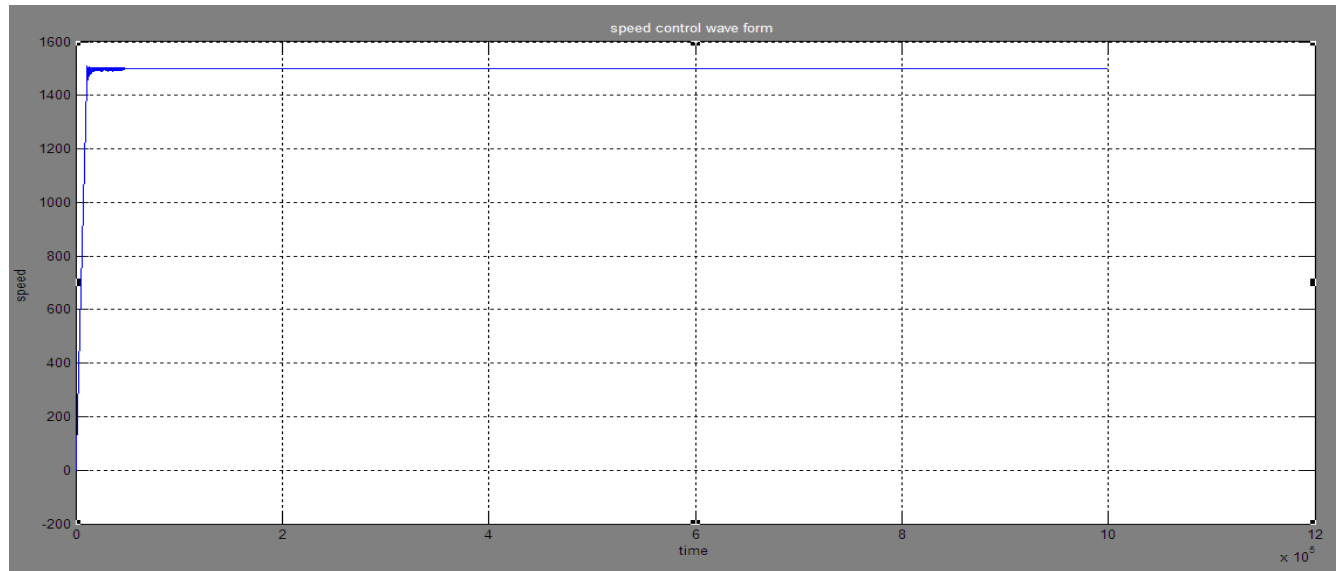

Figure 12.2 speed (vs) Time

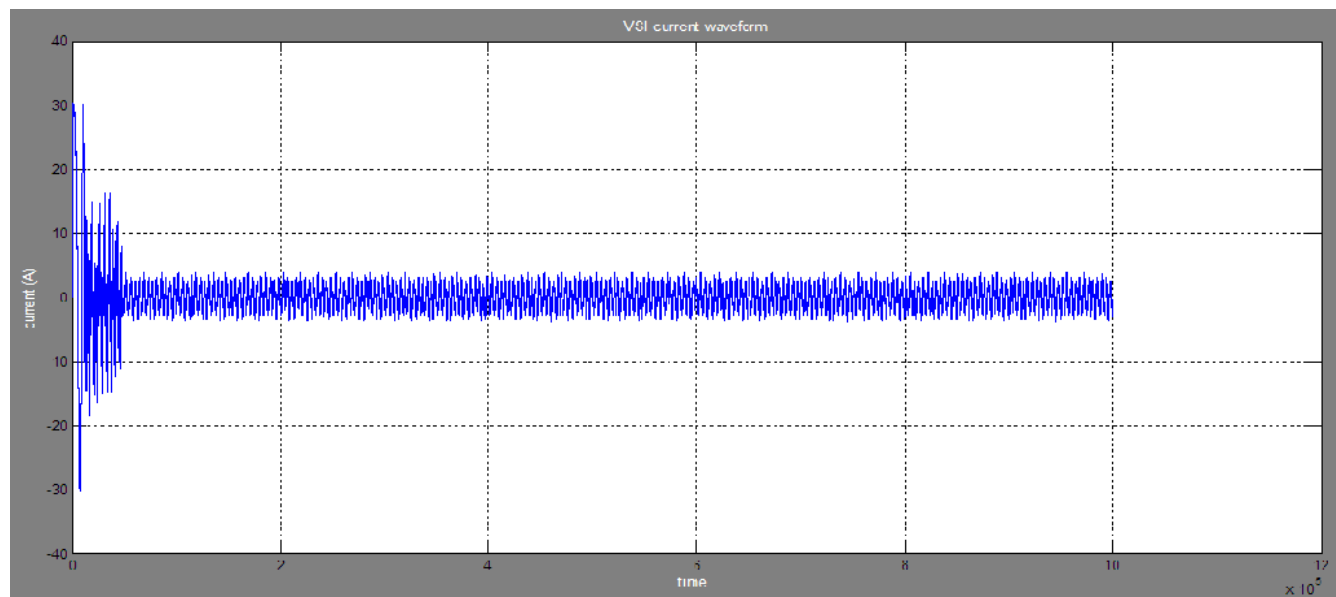

Figure 12.3 VSI wave form 


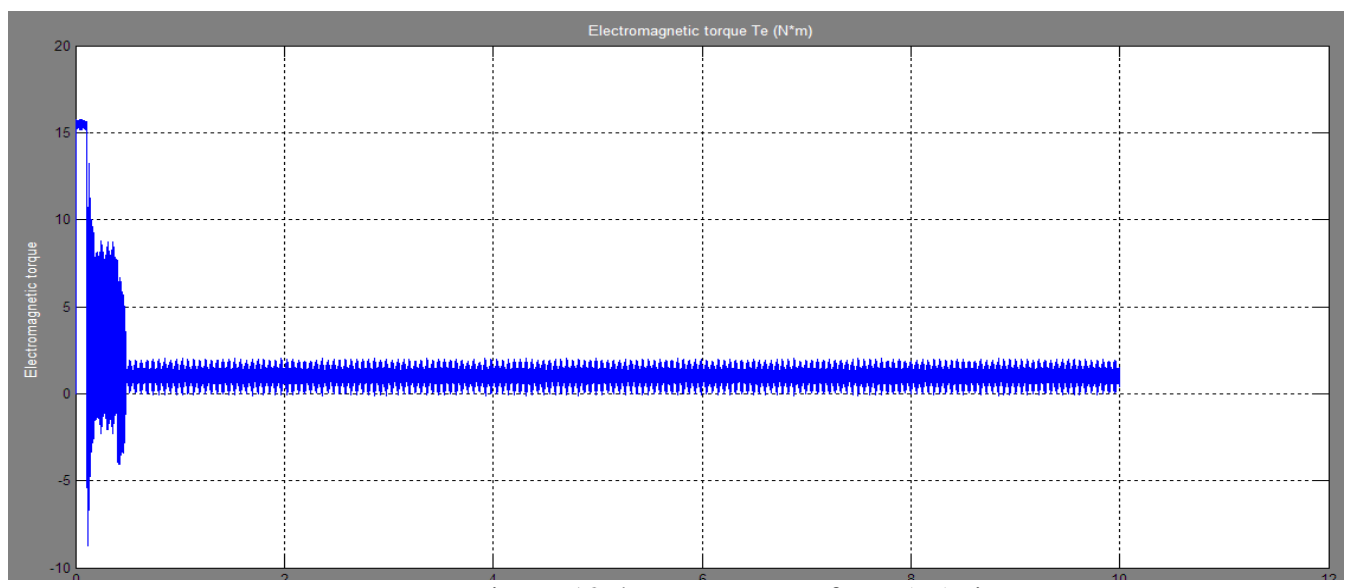

Figure 12.4 Torque wave form (vs) time

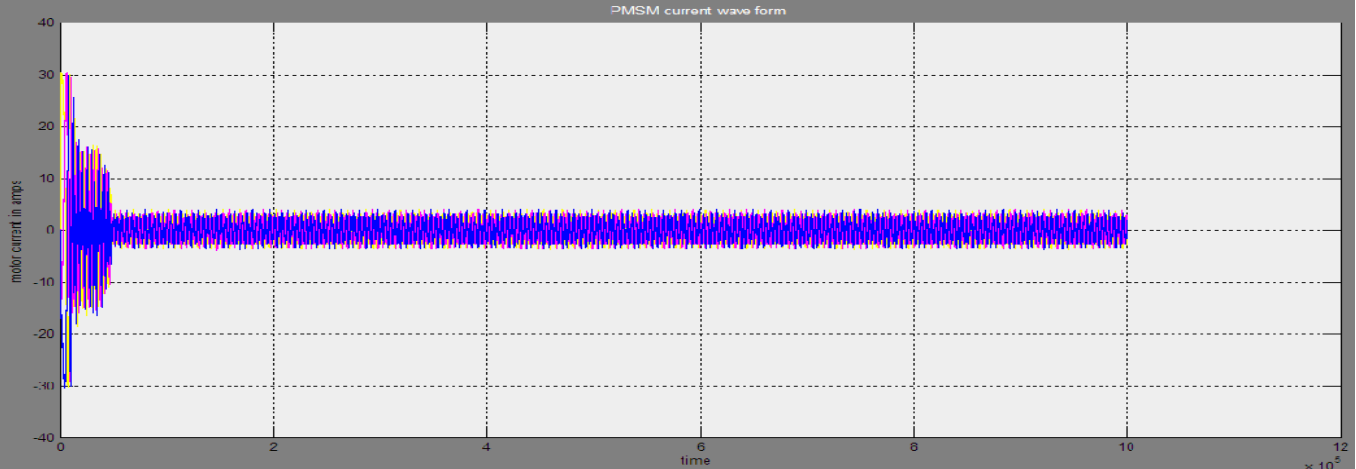

Figure 12.5PMSM current waveform (Vs) Time

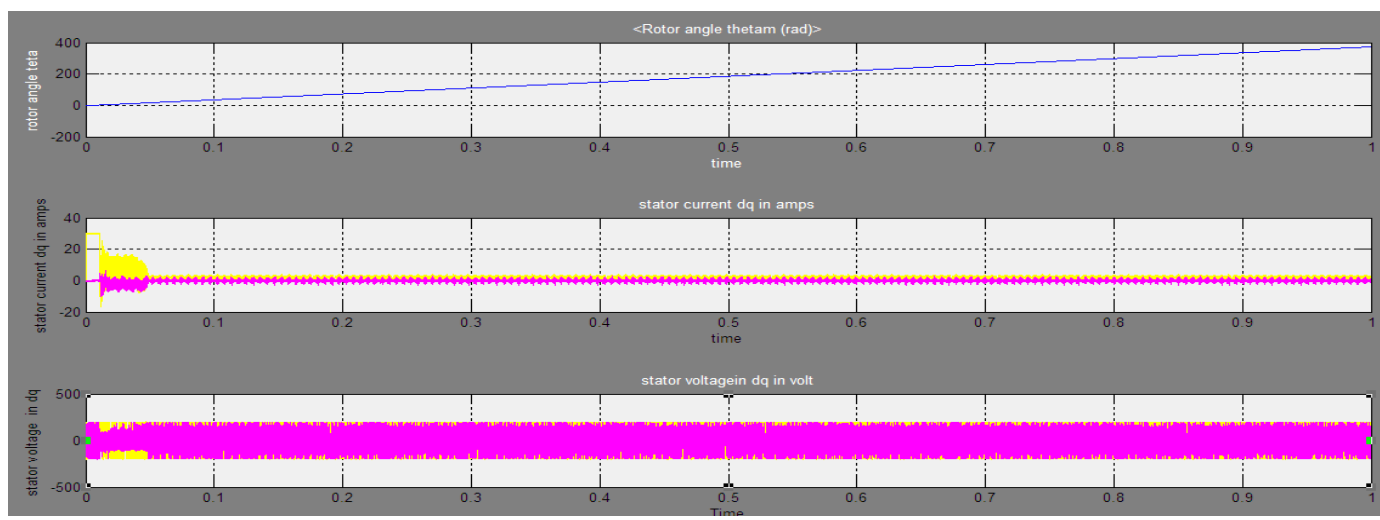

Figure 12.6 (a) Rotor Angle (B) Stator Current Wave Form (C) Dq Stator Current Wave Form

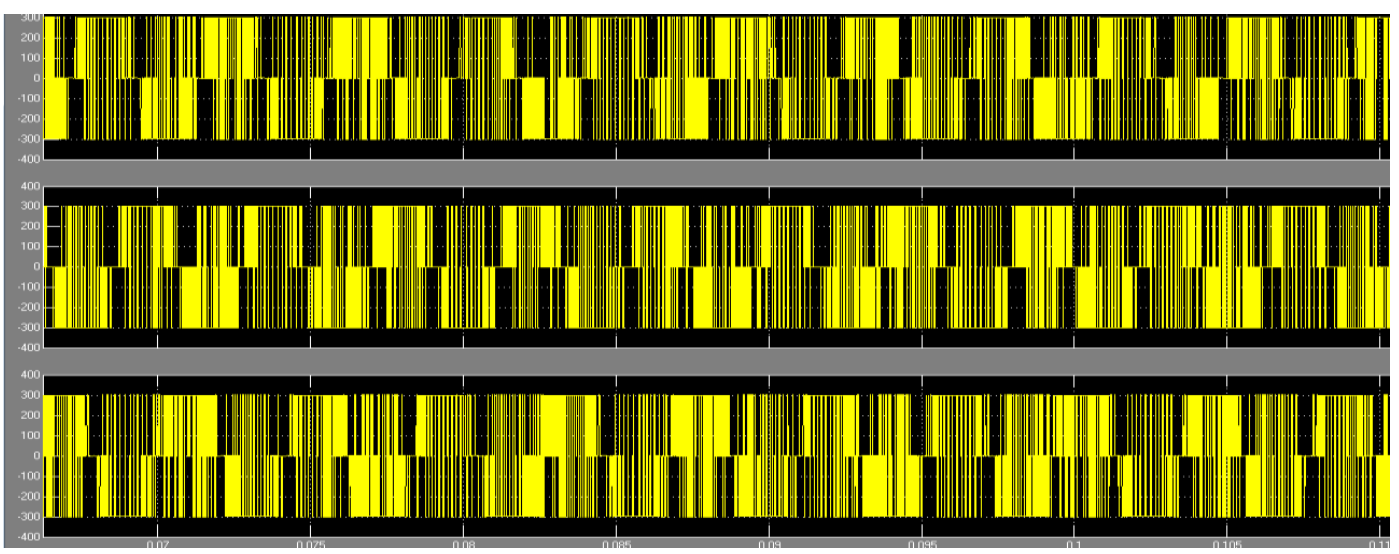

Figure 12.7Va, $\mathrm{V}_{\mathrm{b}}$, Vc Voltage Wave Forms 


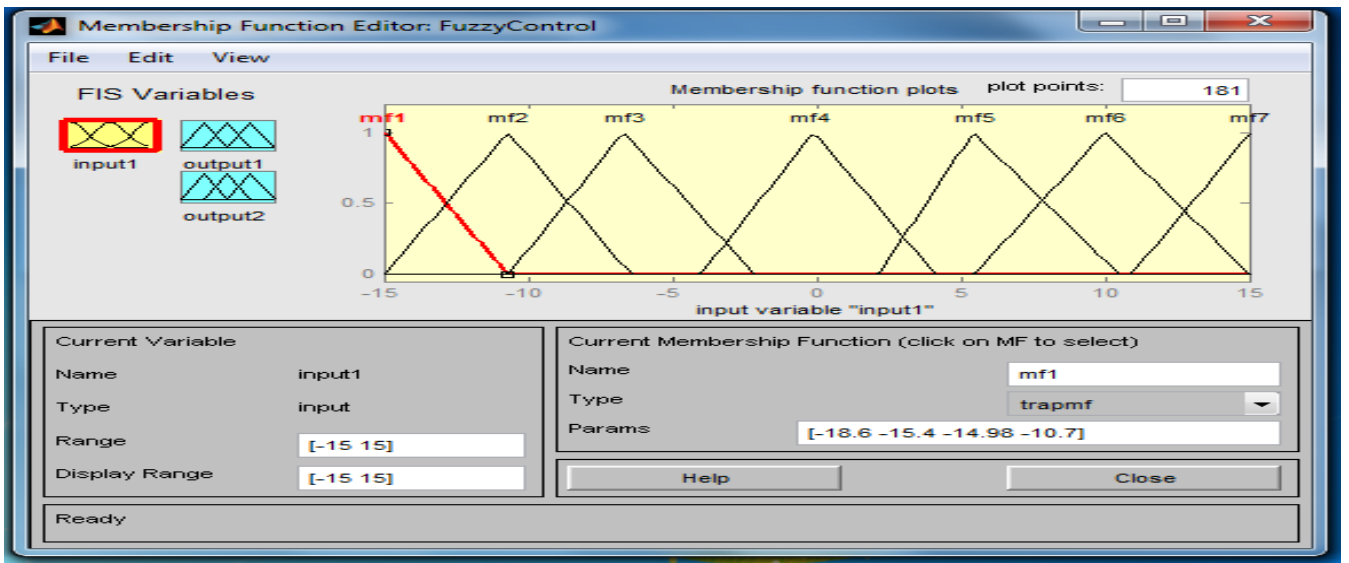

Figure 12.8 Member Ship Function Created In Fuzzy System

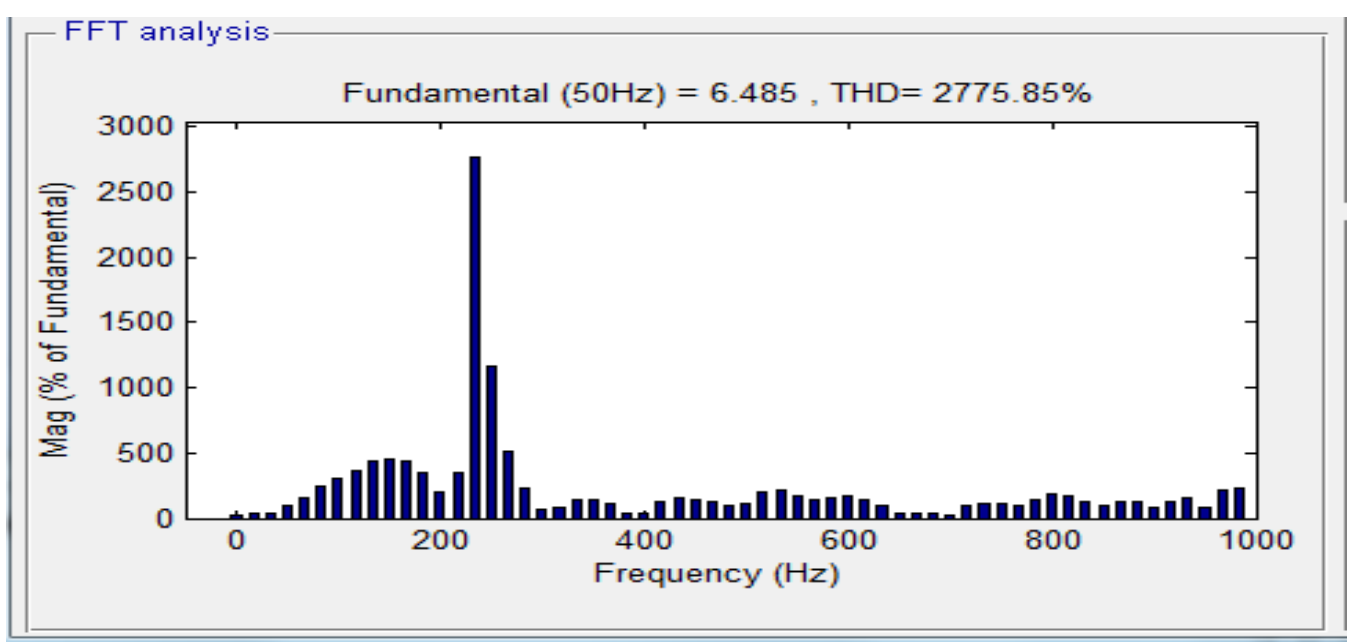

Figure 12.9 FFT Analysis of the Inverter Output

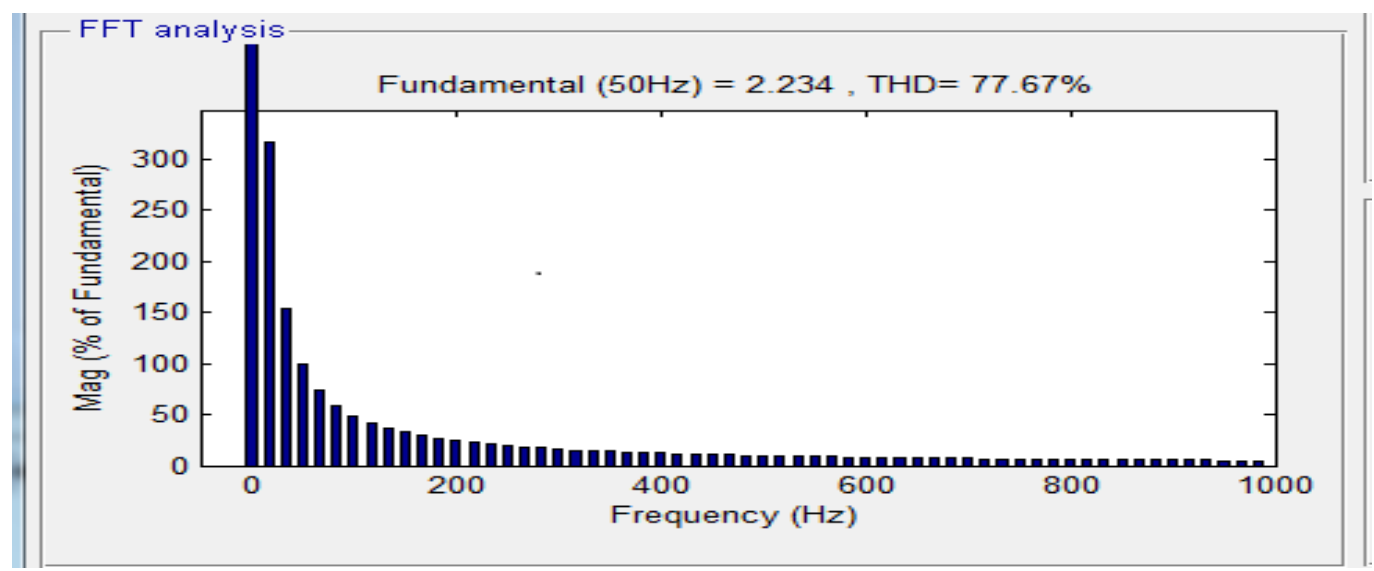

Figure 12.10 Fft Analysis with Dq Current

XIII. PMSM Parameter Assigned

\begin{tabular}{|c|c|}
\hline PARAMETERS & VALUES OPTAINED \\
\hline Waveform & Sinusoidal \\
\hline Voltage & $300 \mathrm{v}$ \\
\hline Motor rated speed & $4000 \mathrm{Rpm}$ \\
\hline Torque & $6 \mathrm{Nm}$ \\
\hline Reference speed & $1500 \mathrm{rpm}$ \\
\hline
\end{tabular}




\section{Simulation Result and Concussion}

In this simulation results shows the normal speed control is better than the v/f control by using VSI fed inverter side the normal speed to is rated steady state speed control is obtained. The fft analysis is taken in $\mathrm{dq}$ current analysis and inverter side fft values. Based on the current controller concept the speed is controlled by comparative analysis with adaptive fuzzy in $\mathrm{K}_{\mathrm{P}}$ and $\mathrm{k}_{\mathrm{i}}$ values are obtained. Compared to the existing method the proposed control have advantages the speed ramped oscillation is controlled the performance has better in proposed scheme.

\section{References}

[1] S. Morimoto, Y. Takeda, and T. Hirasa, "Expansion of operating limits for permanent magnet motor by current vector control considering inverter capacity," IEEE Trans. Ind. Appl., vol. 26, no. 5, pp. 866-871, Sept./Oct. 1990.

[2] J. M. Kim and S. K. Sul, "Speed control of interior permanent magnet Synchronous motor drive for the flux weakening operation," IEEE Trans. Ind. Appl., vol. 33, no. 1, pp. 43-48, Jan./Feb. 1997.

[3] J. Holtz, W. Lotzkat, and M. Khambadkone, "On continuous control of PWM inverters in the overmodulation range including the six-step mode," IEEE Trans. Power Electron., vol. 8, no. 4, pp. 546-553, Oct. 1993.

[4] S. Bolognani and M. Zigliotto, "Novel digital continuous control of SVM inverters in the over modulation range," IEEE Trans. Ind. Appl., vol. 33, no. 2, pp. 525-530, Mar./Apr. 1997

[5] D. C. Lee and G. M. Lee, "A novel overmodulation technique for space-vector PWM inverters," IEEE Trans. Power Electron., vol. 13, no. 6, pp. 1144-1151, Nov. 1998.

[6] T. H. Nguyen, T. L. Van, D. C. Lee, J. H. Park, and J. H. Hwang, "Control mode switching of induction machine drives between vector control and V/f control in overmodulation range,” Journal of Power Electronics, vol. 11, no. 6, pp. 846-855, Nov. 2011

[7] A. M. Hava, R. J. Kerkman, T. A. Lipo, "Carrier-based PWM-VSI overmodulation strategies Analysis, comparison, and design," IEEE Trans. Power Electron., vol. 13, no. 4, pp. 674-689, July 1998

[8] R. Monajemy and R. Krishnan, "Performance comparison for six-step voltage and constant back EMF control strategies for PMSM," in Conf. Rec. IEEE IAS Annu. Meeting, vol.1, no., pp. 165-172

[9] S. Morimoto, Y. Inoue, T. F. Weng, and M. Sananda, "Position sensorless PMSM drive system including square-wave operation at high-speed," in Conf. Rec. IEEE IAS Annu. Meeting, 2007, pp. 676-682.

[10] B. K. Bose, "A high-performance inverter-fed drive system of an interior permanent magnet synchronous machine," IEEE Trans. Ind. Appl., vol. 24, no. 6, pp. 987-1087, Nov./Dec. 1988

\section{Biography}

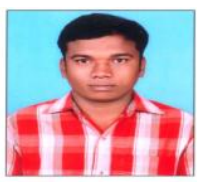

R.Gopala Krishnan completed BE in Electrical and Electronics Engineering in Karpagam university Coimbatore, and persuring $\mathrm{ME}$ in Power Electronics and Drives in P.A college of engineering and technology, Pollachi.

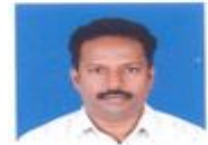

S.Vijayabaskar completed his BE and ME and persuring his Ph.D, in power system. Previously he worked in Kongu College of engineering Perundurai and currently working as an associate professor in P.A College of engineering and technology, pollachi. 